\title{
Article
}

\section{The Recolonization Concentration Concept: Using Avoidance Assays with Soil Organisms to Predict the Recolonization Potential of Contaminated Sites}

\author{
Mathieu Renaud *, ${ }^{*}$, Tiago Natal-da-Luz (D), Rui Ribeiro (D) and José Paulo Sousa (D)
}

check for

updates

Citation: Renaud, M.; Natal-da-Luz,

T.; Ribeiro, R.; Sousa, J.P. The

Recolonization Concentration

Concept: Using Avoidance Assays

with Soil Organisms to Predict the

Recolonization Potential of

Contaminated Sites. Toxics 2022, 10,

127. https://doi.org/10.3390/

toxics 10030127

Academic Editor: Pierre-Marie Badot

Received: 4 February 2022

Accepted: 3 March 2022

Published: 5 March 2022

Publisher's Note: MDPI stays neutral with regard to jurisdictional claims in published maps and institutional affiliations.

Copyright: (C) 2022 by the authors. Licensee MDPI, Basel, Switzerland. This article is an open access article distributed under the terms and conditions of the Creative Commons Attribution (CC BY) license (https:// creativecommons.org/licenses/by/ $4.0 /)$.

\author{
CFE-Centre for Functional Ecology, Associated Laboratory TERRA, Department of Life Sciences, \\ University of Coimbra, Calçada Martim de Freitas, 3000-456 Coimbra, Portugal; tiagonluz@iav.uc.pt (T.N.-d.-L.); \\ rui.ribeiro@zoo.uc.pt (R.R.); jps@zoo.uc.pt (J.P.S.) \\ * Correspondence: mathieu.renaud@centreecotox.ch \\ + Current address: Ecotox Centre-Swiss Centre for Applied Ecotoxicology, EPFL ENAC IIE, GE, Station 2, \\ CH-1015 Lausanne, Switzerland.
}

\begin{abstract}
In this study the recolonization concentration concept for soil organisms is presented and validated. This concept is based on the empirically deduced avoidance-recolonization hypothesis, which shows a negative correlation between avoidance $\left(A C_{x}\right)$ and recolonization $\left(\mathrm{RC}_{\mathrm{x}}\right)$ $\left(A C_{x}=R C_{100-x}\right)$ responses. The concept was validated in a two-step approach composed by (i) individual placement tests, to demonstrate the non-influence of individual placement in a dual chamber avoidance test and (ii) small scale gradient tests to demonstrate that the number of colonizers reaching a soil patch with a certain concentration is independent on their previous exposure to lower concentrations. Overall, data show that avoidance data can be used, when framed under the recolonization concentration concept, to evaluate the recolonization potential of contaminated sites. The recolonization concept is an important theoretical concept that when coupled with spatial modelling tools could be used to tackle the spatial and temporal recovery dynamics of contaminated soil.
\end{abstract}

Keywords: copper; behavior; Eisenia andrei; Folsomia candida

\section{Introduction}

Ecological recovery is a key component to consider when establishing acceptable risk levels for specific protection goals and was considered in proposals for the risk assessment of plant protection products [1-4]. Ecological recovery includes the "community recovery principle" which assumes that the ability of communities to recover allows ecosystems to endure and absorb certain amounts of pollution. As a result, protection goals are allowed to be more permissive because communities are viewed as dynamic systems that can react and recover from stress. In addition to community recovery, risk assessment schemes may also include the species vulnerability concept, an overarching concept which considers not only the species sensitivity to a contaminant, but also its probability of exposure and recovery potential after the occurrence of effects [5].

Recovery at the population level of a previously contaminated site (sensu lato) involves the recolonization, establishment and growth of a population at that site. These processes are dependent on the level of contamination and the existence of a source population either in the edge of the impacted area (external recovery) or from population reservoirs in non-contaminated patches within the impacted area (internal recovery) [6,7]. They are also temporally dependent on the dispersal ability of organisms [8,9], which can be influenced by habitat quality (e.g., food availability) and structure [10-12]. The actual knowledge on the recolonization of contaminated sites by soil fauna is relatively scarce. Some studies have shown the effects of different levels of pesticide mixtures on the recolonization of soil microarthropod and macrofauna communities $[6,7,13]$ and the effect of copper on the recolonization of an abandoned arable soil by earthworms [14]. 
At the ecosystem level or even community level, understanding recovery is a complex task which requires the combined use of experimentation and modelling tools. In fact, an EFSA scientific opinion [4] has highlighted that if community recovery is to be considered in the risk assessment of plant protection products, then population models and specifically spatially and temporally based population models need to be included to tackle population dynamics and their recovery in fields. The use of population models in ecological risk assessment has been widely discussed [15-17] and, for in-soil organisms, individual- and matrix-based models have been developed with the collembolan Folsomia candida addressing both toxic effects and recolonization issues [18-20]. Besides the need to expand these models to other key species of soil fauna from different ecological groups, models must also be improved by including a wider variety of trait data (mainly life history and dispersal traits) obtained by experimentation. For this goal, standard ecotoxicological tests can provide information on toxic effects on several life-history traits (e.g., growth, reproduction). However, for recolonization acquiring experimental data is more difficult since no simple standardized test exists to evaluate the recolonization potential of a soil contaminated with a certain concentration of a chemical. In this paper, we aimed at demonstrating that data from avoidance tests can be used to address the recolonization potential of contaminated soil patches.

Avoidance tests, such as those performed with the collembolan F. candida and the earthworm Eisenia andrei $[21,22]$, are a sensitive and cost-effective screening tool to assess toxic effects, especially in site-specific risk assessment [23-25]. Avoidance responses towards a certain level of contamination can influence dispersal processes directly, providing important hints about the recolonization process. In fact, some studies have already demonstrated that avoidance behavior is tightly related with the spatial distribution of soil animals in patchily contaminated soils [26] and functions as a behavioral mechanism that allows organisms to reduce their exposure to contaminants [27].

A contaminated habitat losing its populations through avoidance will be recolonized as soon as the concentration of the contaminant is sufficiently reduced to become undetected and, thus, unavoided. Therefore, it is expected that the proportion of organisms avoiding a contaminant at a given concentration is negatively correlated with the proportion of organisms unable to detect it and, thus, able to occupy this contaminated habitat. In other words, a contaminant concentration causing a certain percentage of organism avoidance $(\mathrm{x}$, in $\%)$ is expected to allow the remaining organisms to colonize this habitat $(100-\mathrm{x}$, in \%). This logically deduced prediction - the avoidance-recolonization hypothesis-has its formulation as follows: $\mathrm{AC}_{\mathrm{x}}=\mathrm{RC}_{100-\mathrm{x}}$, where $\mathrm{AC}_{\mathrm{x}}$ (avoidance concentration) is the contaminant concentration eliciting an $\mathrm{x} \%$ of avoidance and RC (recolonization concentration) is the contaminant concentration allowing a $100-x \%$ of recolonization. In fact, this hypothesis, the avoidance-recolonization hypothesis, has been demonstrated in the aquatic environment with the model species Daphnia magna [28].

For this hypothesis to hold true, one assumption needs to be fulfilled: the number of organisms avoiding (when placed in the contaminated soil) and the number of organisms colonizing (when placed in the control soil) a habitat patch presenting a certain concentration of a chemical is not different within an avoidance test. However, in contaminated sites, it is common that gradients of contamination are observed and as such, it is also important for the $\mathrm{RC}_{\mathrm{x}}$ concept that the number of organisms colonizing a certain soil patch is unaffected by the pattern of previous exposure to lower concentrations those organisms experienced along the gradient.

In the present study, experiments using two key species of soil fauna (the earthworm E. andrei and the collembolan F. candida), avoidance behavior as the endpoint and copper as a model substance were performed to empirically validate the avoidance-recolonization hypothesis. To attain this goal, three experimental setups were performed: (1) dual chamber avoidance test to estimate $\mathrm{AC}_{\mathrm{x}}$ values; (2) dual chamber avoidance tests with the introduction of the test organisms in different areas of the test units to confirm that the final distribution of the test organisms is independent of their initial position; and (3) small-scale 
gradient tests using test vessels divided into three sections to confirm that the number of colonizers reaching a soil with a certain level of contamination is not influenced by a previous exposure to lower concentrations of the same contaminant.

\section{Material and Methods}

\subsection{Test Soil}

A sandy-loam natural soil collected from an agricultural field in the suburban limits of the city of Coimbra, Portugal, was used as the test soil. This soil was free of pesticide or fertilizer applications for more than five years. Background copper concentrations were measured in the soil (control samples) for each of the current experiments as described below and averaged $29.4 \pm 2.6 \mathrm{mg} / \mathrm{kg}$. The soil was collected from the top $20 \mathrm{~cm}$ layer, sieved at $5 \mathrm{~mm}$ and defaunated through two freeze-thaw cycles $\left(48 \mathrm{~h}\right.$ at $-20{ }^{\circ} \mathrm{C}$ followed by $48 \mathrm{~h}$ at $25^{\circ} \mathrm{C}$ ). Physical and chemical parameters measured (Table 1) were texture [29], water-holding capacity [30], pH (1 M KCl 1:6 v:v), organic matter content (loss on ignition at $500{ }^{\circ} \mathrm{C}$ for $6 \mathrm{~h}$ ), total $\mathrm{N}$ [31] and cation exchange capacity [32].

Table 1. Chemical and physical characterization of the test soil.

\begin{tabular}{cc}
\hline Parameter & Value \\
\hline Water-holding capacity & $36.2 \pm 0.4 \%$ \\
Organic matter & $3.3 \pm 0.1 \%$ \\
pH $(\mathrm{KCl} 1 \mathrm{M})$ & 6.9 \\
Total N & $0.83 \mathrm{mg} / \mathrm{g}$ \\
Cation-exchange capacity & $0.0125 \mathrm{cmol} / \mathrm{g}$ \\
Sand & $62.40 \%$ \\
Silt & $21.20 \%$ \\
Soil texture class & $16.40 \%$ \\
Soil type & Sandy-loam \\
\hline
\end{tabular}

\subsection{Test Organisms and Culture Conditions}

Earthworms from the species Eisenia andrei (Oligochaeta: Lumbricidae) and springtails from the species Folsomia candida (Collembola: Isotomidae) were used as test organisms in the experiments. These species are currently used in avoidances tests $[23,24]$ and have standardized ISO guidelines for this type of test [21,22]. Both test species were obtained from laboratory cultures reared under a photoperiod of 16:8 h light:dark at $20 \pm 2{ }^{\circ} \mathrm{C}$. The earthworms were kept in plastic containers $(36 \mathrm{~cm}$ length, $22 \mathrm{~cm}$ width, and $11 \mathrm{~cm}$ height) using horse manure and Sphagnum sp. peat as substrate in a ratio of 1:1 (w:w). Cooked oatmeal was given as food twice a month. Springtails were cultured in cylindrical transparent plastic boxes (11 cm diameter and $4 \mathrm{~cm}$ height) using a mixture of plaster of Paris and activated charcoal in a ratio of 11:1 (w:w) as the substrate. Granulated dry yeast was added as food in small amounts to avoid spoilage by fungi. Moldy food was removed from the culture containers when detected.

\section{Experimental Procedure}

At the start of all experiments, soil moisture was adjusted to $50 \%$ of its water-holding capacity. Copper sulphate $\left(\mathrm{CuSO}_{4}\right.$, Sigma, Steinheim, Germany) spiked soils with different concentrations (see Table 2) were prepared for three different experimental setups: avoidance tests, individual placement tests and small-scale gradient tests. For each set of experiments, different spiking solutions were prepared by diluting a specific volume of a copper sulphate stock solution in distilled water (similar final volume for each spiking solution) to attain the desired test concentrations. These spiking solutions were mixed directly in specific portions of soil immediately before its use in experiments. 
Table 2. Nominal concentrations (expected) and total and extractable concentrations (measured; average \pm standard deviation) of copper in soil treatments used in the avoidance tests, individual placement tests, small-scale gradient tests and large-scale gradient tests, using Eisenia andrei or Folsomia candida as test organisms. E0-E7 and C0-C4 refer to treatments used in avoidance tests with $E$. andrei and F. candida, $\mathrm{AC}_{20}-\mathrm{AC}_{80}$, avoidance concentrations (estimated the initial avoidance tests), used in the other tests for each species, respectively.

\begin{tabular}{|c|c|c|c|c|c|}
\hline & & \multirow{2}{*}{$\begin{array}{c}\text { Nominal } \\
\text { (mg/kg) }\end{array}$} & \multirow{2}{*}{$n$} & Total Copper & Extractable Copper \\
\hline & & & & (mg/kg) & (mg/kg) \\
\hline \multirow[t]{11}{*}{ Eisenia andrei } & E0/CT & 0 & 15 & $29.37 \pm 2.64$ & $0.06 \pm 0.12$ \\
\hline & E1 & 5 & 3 & $34.45 \pm 3.77$ & $0.05 \pm 0.03$ \\
\hline & E2 & 10 & 3 & $48.25 \pm 3.59$ & $0.06 \pm 0.1$ \\
\hline & E3 & 25 & 3 & $54.27 \pm 7.49$ & $0.58 \pm 0.23$ \\
\hline & E4 & 50 & 3 & $89.12 \pm 5.42$ & $1.20 \pm 0.07$ \\
\hline & E5 & 100 & 3 & $140.60 \pm 3.71$ & $5.42 \pm 0.45$ \\
\hline & E6 & 200 & 3 & $239.99 \pm 31.36$ & $22.11 \pm 2.60$ \\
\hline & E7 & 400 & 3 & $551.57 \pm 30.6$ & $73.2 \pm 5.80$ \\
\hline & $\mathrm{AC}_{20}$ & 20 & 9 & $50.79 \pm 4.48$ & $0.42 \pm 0.15$ \\
\hline & $\mathrm{AC}_{50}$ & 50 & 6 & $74.49 \pm 9.59$ & $1.90 \pm 0.28$ \\
\hline & $\mathrm{AC}_{80}$ & 100 & 6 & $147.09 \pm 15.43$ & $5.66 \pm 0.61$ \\
\hline \multirow[t]{8}{*}{ Folsomia candida } & $\mathrm{C} 0 / \mathrm{CT}$ & 0 & 9 & $30.21 \pm 3.77$ & $0 \pm 0.16$ \\
\hline & C1 & 100 & 3 & $185.29 \pm 18.44$ & $6.87 \pm 0.44$ \\
\hline & $\mathrm{C} 2$ & 200 & 3 & $330.84 \pm 21.46$ & $26.15 \pm 0.27$ \\
\hline & $\mathrm{C} 3$ & 800 & 3 & $1173.89 \pm 22.30$ & $159.25 \pm 21.66$ \\
\hline & $\mathrm{C} 4$ & 1600 & 3 & $2257.49 \pm 34.95$ & $709.91 \pm 77.53$ \\
\hline & $\mathrm{AC}_{20}$ & 300 & 6 & $382.36 \pm 47.44$ & $42.50 \pm 9.80$ \\
\hline & $\mathrm{AC}_{50}$ & 1000 & 6 & $1061.51 \pm 71.79$ & $264.28 \pm 46.70$ \\
\hline & $\mathrm{AC}_{80}$ & 3300 & 6 & $3765.78 \pm 276.73$ & $1466.79 \pm 143.88$ \\
\hline
\end{tabular}

\subsection{Avoidance Tests}

Dual chamber avoidance tests were performed with earthworms and springtails following procedures based on the ISO guidelines 17512-1 [21] and 17512-2 [22], respectively. Combinations (control vs. copper spiked soil) using a range of copper contaminated soils (see nominal copper concentrations in Table 2) were tested to define avoidance concentration values $\left(\mathrm{AC}_{\mathrm{x}}\right)$ of copper that induce 20,50 and $80 \%$ avoidance behavior $\left(\mathrm{AC}_{20}\right.$, $\mathrm{AC}_{50}$ and $\mathrm{AC}_{80}$, respectively) for each test species. Additionally, a dual-control test with uncontaminated soil in both sections of the test vessels was performed to validate the test. These tests were performed at $20 \pm 2{ }^{\circ} \mathrm{C}$ under a photoperiod of $16: 8 \mathrm{~h}$, light:dark.

For avoidance tests with earthworms, each test vessel consisted of a plastic box $(20 \mathrm{~cm}$ length, $12 \mathrm{~cm}$ width, and $5 \mathrm{~cm}$ height) divided into two sections by a card divider. In each section, $250 \mathrm{~g}$ (dry weight equivalent; DW) of uncontaminated or copper contaminated soil were placed. Twenty adult earthworms were placed in the middle line between both sections after removing the card divider. Five replicates were prepared per combination. For springtails, the procedures adopted were similar to those used for earthworm tests but cylindrical plastic boxes $(7 \mathrm{~cm}$ diameter, $6 \mathrm{~cm}$ height) were used as test vessels and $30 \mathrm{~g}$ (fresh weight equivalent; FW) of soil was placed in each section. Twenty springtails 10- to 12-days old (taken from synchronized cultures) were placed in the middle line between sections after removing the card divider. Five replicates were prepared per combination. Samples were obtained from each soil at the start of the experiment to measure initial $\mathrm{pH}$ and soil water content. A visual depiction of the test vessels is provided in Figure 1. 
AVOIDANCE
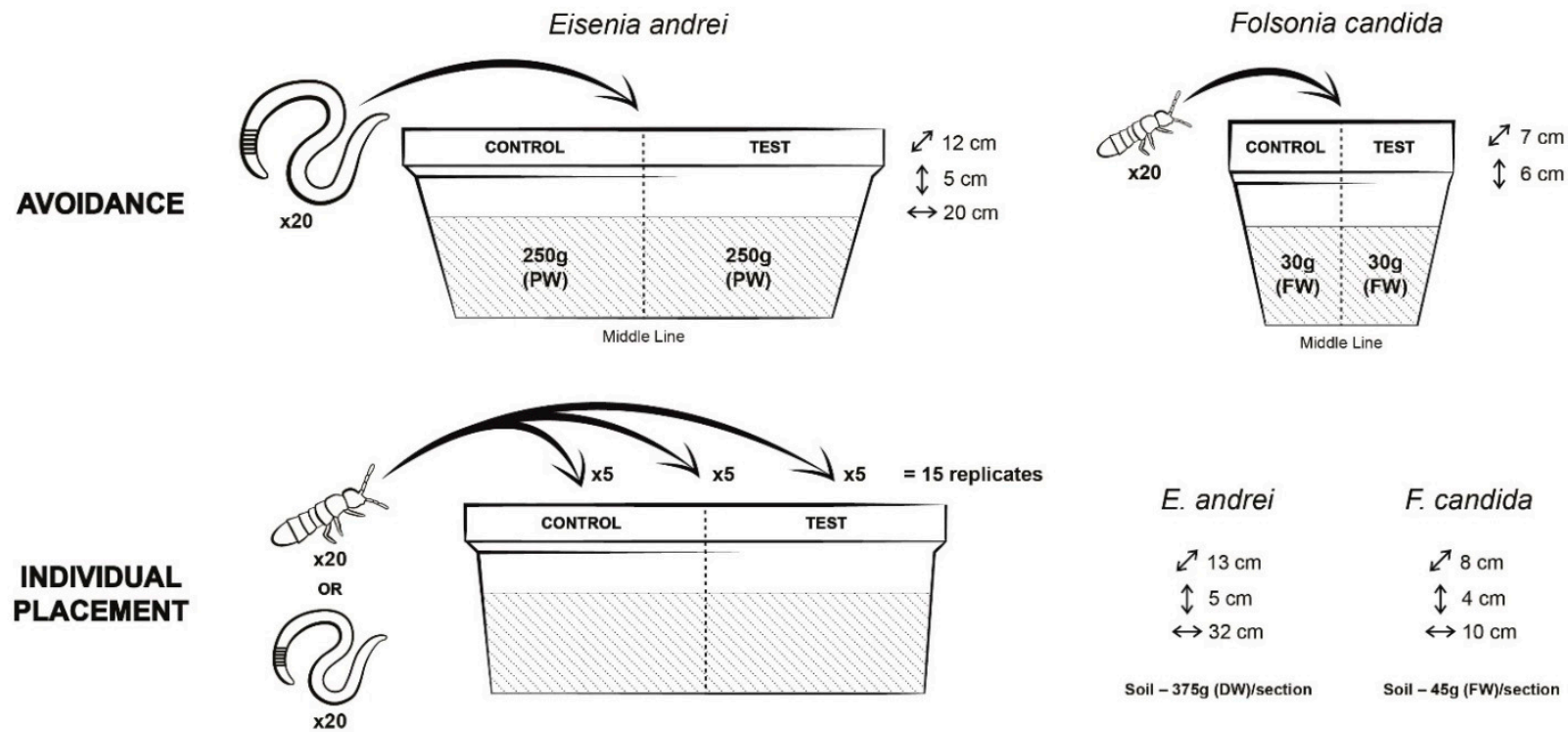

SMALL SCALE GRADIENT

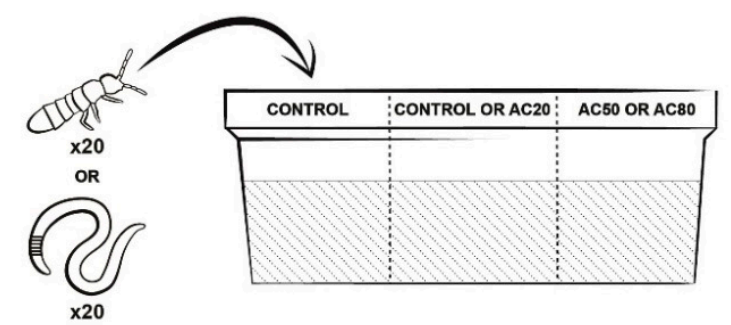

$\begin{array}{cc}\text { E. andrei } & \text { F. candida } \\ \swarrow^{\nearrow} 13 \mathrm{~cm} & \nwarrow 8 \mathrm{~cm} \\ \uparrow 5 \mathrm{~cm} & \uparrow 4 \mathrm{~cm} \\ \leftrightarrow 32 \mathrm{~cm} & \leftrightarrow 10 \mathrm{~cm} \\ \text { Soil - 250g (DW)/section } & \text { Soil }-\mathbf{3 0 g}(\mathrm{FW}) / \text { section }\end{array}$

Figure 1. Visual scheme depicting test vessels and experimental procedures for the avoidance, individual placement and small-scale gradient tests.

For both avoidance tests with earthworms and springtails, the test period was of $48 \mathrm{~h}$, after which plastic dividers were carefully reintroduced separating the two soil test sections. For earthworms, the soil in each section was transferred to plastic trays and the number of earthworms was counted by hand sorting. For collembola, the soil in one section was transferred to a small plastic vessel of the same size. The plastic divider was then removed and the soil in each vessel was flooded with water, a few drops of dark ink were added and after gentle stirring the number of springtails floating on the water surface was determined.

In the following set of experiments, copper concentrations used were defined according to the $\mathrm{AC}_{\mathrm{x}}$ concentrations estimated for each species in these avoidance tests. These experiments were conducted to empirically demonstrate the avoidance-recolonization hypothesis and validate the $\mathrm{RC}_{\mathrm{x}}$ concept. For the individual placement and small-scale gradient experiments, slightly larger and different test vessels were used to allow a better division into three sections for the gradient test. As a result, a larger amount of soil (but with the same amount of total soil between individual placement and small-scale gradient tests) was used. The larger test vessels and soil were not used for the avoidance tests as these were conducted following standard guidelines in order to allow a better comparability with other avoidance experiments. The different test vessels and experimental procedures are visually depicted in Figure 1.

\subsection{Individual Placement Tests}

These assays were adapted from the ISO guidelines 17512-1 [21] and ISO 17512-2 [22] for earthworms and springtails, respectively. The procedures adopted were similar to those used for avoidance tests with some differences. For the individual placement tests with earthworms, plastic boxes (32 cm length, $13 \mathrm{~cm}$ width and $5 \mathrm{~cm}$ height) were used 
and each section was filled with $375 \mathrm{~g}$ of soil (DW). For tests with springtails, plastic boxes (10 cm length, $8 \mathrm{~cm}$ width and $4 \mathrm{~cm}$ height) were used and $45 \mathrm{~g}$ of soil (FW) was placed in each section. Contaminated soils with copper concentrations corresponding to the $\mathrm{AC}_{20}, \mathrm{AC}_{50}$ and $\mathrm{AC}_{80}$ (estimated for each species in the previous set of tests) were tested against the control (uncontaminated) soil. A total of 15 replicates were prepared for each soil combination. These 15 replicates were sub-divided into three groups of 5 replicates where the organisms were introduced in three different locations of the test containers: in the middle line between both sections (as performed in a standard dual chamber avoidance test), in the section with contaminated soil (an avoidance scenario) or in the section with uncontaminated soil (a recolonization scenario). The procedures are visually depicted in Figure 1. In addition to treatments with contaminated soil, ten replicates with uncontaminated soil in both sections were prepared (dual-control test) to demonstrate that no avoidance occurs when the same soil is placed in both sections of the replicates. In this case, in half of the replicates the organisms were placed in the middle line of the test containers and in the other half in one of the sections. After $48 \mathrm{~h}$, the number of individuals in each section was determined adopting the same methodology used in the previous avoidance tests.

\subsection{Small-Scale Gradient Tests}

Each test vessel (same size of those used in the individual placement tests) was divided into three equal sections, using two plastic dividers. For tests with earthworms, $250 \mathrm{~g}$ of soil (DW) was placed in each section and for springtails tests, $30 \mathrm{~g}$ of soil (FW) was used. Four combinations were tested using uncontaminated soil (CT) and copper spiked soils with corresponding $\mathrm{AC}_{20}, \mathrm{AC}_{50}$ and $\mathrm{AC}_{80}$ concentrations for each species. The sequences tested were CT-CT-AC $\mathrm{C}_{50}$ and CT-CT-AC 80 (without an intermediate copper contaminated soil) that worked as control for the combinations CT-AC $\mathrm{C}_{20}-\mathrm{AC} 50$ and CT-AC $\mathrm{C}_{20}-\mathrm{AC}_{80}$, respectively. Each combination was performed with 5 replicates for both test species. Soil samples were collected from each treatment at the beginning of the test to measure initial $\mathrm{pH}$ and soil water content.

After removing the plastic dividers, 20 individuals of each test species were placed in the border section of the test vessel with uncontaminated soil (Ct). After $48 \mathrm{~h}$, the plastic dividers were reintroduced in their previous positions and the number of surviving organisms was determined in each section following procedures described for the avoidance tests.

\section{Metal Analysis}

For total copper concentrations, $80-100 \mathrm{mg}$ samples of oven dried (at $105^{\circ} \mathrm{C}$ for $12 \mathrm{~h}$ ) and homogenized soil were used in triplicate for each treatment. Each sample was mixed with $2 \mathrm{~mL}$ of $69 \%$ nitric acid (PA-AC-ISO, Panreac, Barcelona, Spain) and left under pressure in a PDS-6 system (Loftfields analytical solutions, Neu Eichenberg, Germany) at $150{ }^{\circ} \mathrm{C}$ for $10 \mathrm{~h}$. After this period, $8 \mathrm{~mL}$ of distilled water was added to the resulting solution and the final volume of $10 \mathrm{~mL}$ was transferred to a plastic vial. A blank with no soil was also prepared adopting the same procedure. The accuracy of this analysis was checked using SRM 2709 (San Joaquin soil—standard reference material) certified by the National Institute of Standards and Technology (Department of Commerce, Washington, DC, USA), average recovery of copper was $107.4 \pm 15.4 \%$ in the reference material.

The extractable copper concentration was determined by stirring $2 \mathrm{~g}$ of air-dried soil with $20 \mathrm{~mL}$ of $1 \mathrm{M}$ ammonium acetate $\left(\mathrm{CH}_{3} \mathrm{COONH}_{4}\right.$ - Sigma, Steinheim, Germany) solution at $400 \mathrm{rpm}$ for $2 \mathrm{~h}$. After this period the resulting solution was filtered through a Whatman $n^{\circ} 1$ filter paper disc (Cat. $\mathrm{N}^{\circ} 1001150$, Maidstone, England) and stored in plastic vials. This procedure was performed in triplicate for each test treatment and a blank with no soil was also prepared.

Total and extractable copper concentrations were determined by flame AAS (2380 Absorption Atomic Spectrometer, Perkin-Elmer). 


\section{Statistical Analysis}

In dual chamber avoidance tests, the significance of the avoidance behavior was tested using the Fisher exact test as described by Natal-da-Luz et al. [23]. The percentage of avoidance response of both $E$. andrei and F. candida was calculated according to the formula $A=C-T / N \times 100$ (where $C$ is the number of individuals in the control soil, $T$ is the number of individuals in contaminated soil and $N$ is the total number of individuals $[20,21])$. The nominal copper concentration at which a specific percentage of avoidance response $\left(\mathrm{AC}_{\mathrm{x}}\right)$ is detected was estimated using the PriProbit 1.63 software [33].

Data obtained in the individual placement tests were analyzed by Fisher exact test. This statistical tool was used to compare the distribution of organisms in replicates where collembolans were introduced in the middle line of the test containers (expected distribution) with that of replicates where the organisms were introduced in one of the test sections (observed distribution). The null hypothesis assumes an equal final distribution of the organisms independently of their initial position (either introducing the organisms in the middle line of the test vessels or introducing the organisms in one of the test sections).

In the small-scale gradient tests, data sets were analyzed by Fisher exact tests comparing the proportion of individuals found in the final section (section opposite to that where the organisms were introduced) of the combinations $\mathrm{Ct}-\mathrm{Ct}-\mathrm{AC} \mathrm{C}_{50}$ and $\mathrm{Ct}-\mathrm{Ct}-\mathrm{AC} \mathrm{C}_{80}$ (expected distribution) with that of the combinations $\mathrm{Ct}-\mathrm{AC}_{20}-\mathrm{AC} \mathrm{C}_{50}$ and $\mathrm{Ct}-\mathrm{AC}_{20}-\mathrm{AC}_{80}$, respectively (observed distribution). In this test, the null hypothesis assumed an equal proportion of colonizing individuals in the final section $\left(\mathrm{AC}_{50}\right.$ or $\mathrm{AC}_{80}$ section) in treatments with and without a lower copper concentration $\left(\mathrm{AC}_{20}\right)$ in the previous section.

Fischer exact tests were calculated using the freely available online calculator for contingency tables (available at https: / www.graphpad.com/quickcalcs/contingency1/ last accessed 31 January 2022).

\section{Results}

Chemical and physical characterization of the soil used in all experimental testing is presented in Table 1. To attest for dosing procedures of the test soil, copper concentrations were measured and are presented in Table 2. Total copper concentrations were always higher than nominal concentrations due to the presence of residual copper in the soil. However, both total and extractable copper concentrations measured showed that the relative copper values between test concentrations were consistent with those of nominal concentrations (Table 2).

\subsection{Avoidance Tests}

Initial avoidance tests were performed to determine avoidance concentration values for all following experimental setups. In these tests mortality was always, on average, lower than $3 \%$ in all combinations tested for both test organisms. The avoidance response observed increased with the increasing copper concentrations for both test species (Figure 2). E. andrei significantly avoided concentrations higher or equal to $25 \mathrm{mg} \mathrm{Cu} / \mathrm{kg}$ soil DW, while $F$. candida showed significant avoidance behavior at a nominal copper concentration higher or equal to $200 \mathrm{mg} \mathrm{Cu} / \mathrm{kg}$ soil DW. The $\mathrm{AC}_{\mathrm{x}}$ values estimated for both test species are shown in Table 3. 


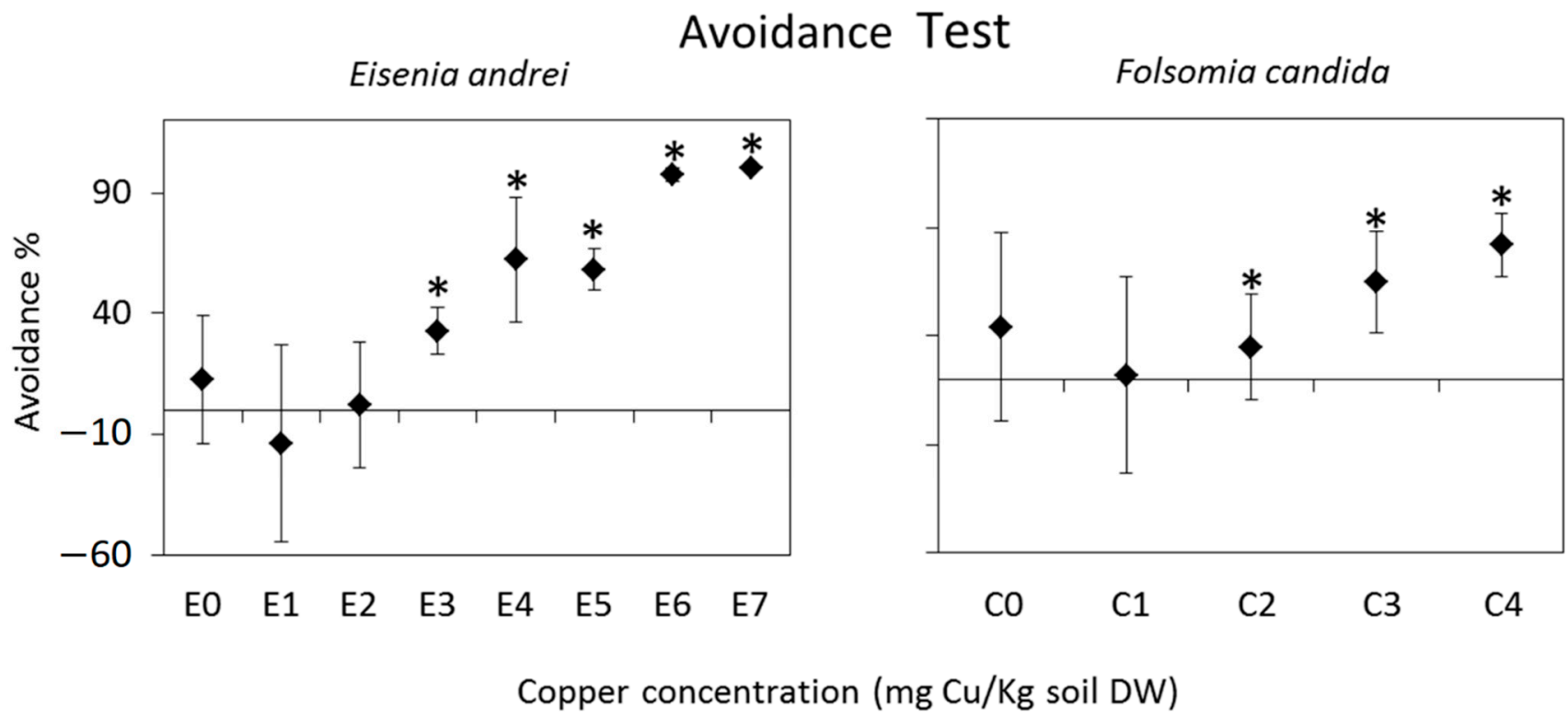

Figure 2. Avoidance tests with Eisenia andrei and Folsomia candida. Percentage of avoidance (average \pm standard deviation; $n=5$ ) in test units combining uncontaminated soil with a copper contaminated soil. * indicates significant avoidance response $(p \leq 0.05)$ after Fisher exact test.

Table 3. Avoidance concentrations ( $\mathrm{AC}_{\mathrm{x}}$; with corresponding $95 \%$ confidence intervals) estimated for Eisenia andrei and Folsomia candida exposed to concentration gradients of copper spiked soil. $\mathrm{AC}_{\mathrm{x}}$ values are expressed in $\mathrm{mg}$ of $\mathrm{Cu}$ per $\mathrm{kg}$ of soil (dry weight equivalent).

\begin{tabular}{ccc}
\hline $\mathrm{AC}_{\mathbf{x}}$ & Eisenia andrei & Folsomia candida \\
\hline $\mathrm{AC}_{20}$ & $21.8(3.9-39.7)$ & $301(49.8-527)$ \\
$\mathrm{AC}_{50}$ & $49.5(20.6-78.0)$ & $1008(601-1890)$ \\
$\mathrm{AC}_{80}$ & $112(70.9-237)$ & $3371(1824-26,987)$ \\
\hline
\end{tabular}

\subsection{Individual Placement Test}

Individual placement tests aimed at demonstrating that the final distribution of organisms after $48 \mathrm{~h}$ is not dependent on their initial position (middle line, control/test soil) in dual chamber avoidance tests combining different copper concentrations $\left(\mathrm{AC}_{20}, \mathrm{AC}_{50}\right.$ and $\mathrm{AC}_{80}$ ) with uncontaminated soil (Figure 3 ). In these experiments, no mortality was observed for E. andrei and mortality of $F$. candida was, on average, lower or equal to $6 \%$ for all treatments. Regarding the statistical analysis of the different treatments (placement in different sections vs. placement in the middle line) no significant difference was found except for $E$. andrei in the $\mathrm{AC}_{50}$ treatment where the combination with individuals placed in the test soil were significantly different from controls $(p<0.05$, introduction of organisms in middle line). 


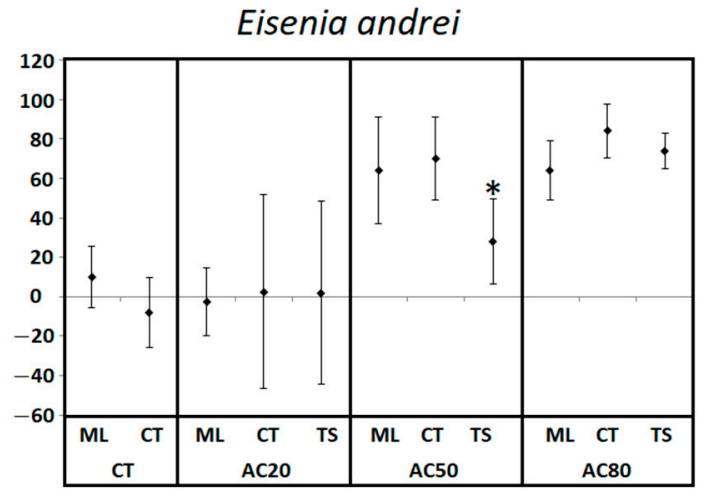

Figure 3. Placement tests with Eisenia andrei and Folsomia candida. Percentage of avoidance (average \pm standard deviation; $n=5$ ) in test units combining uncontaminated soil $(\mathrm{Ct})$ with $\mathrm{Ct}$ or copper contaminated soils equivalent to $\mathrm{AC}_{20}, \mathrm{AC}_{50}$ and $\mathrm{AC}_{80}$ concentrations. For each of these combinations individuals were placed in the middle line (ML), in the control soil (CT), or in the test soil (TS). * indicates a significant difference from the combinations where individuals were placed in the middle $(p \leq 0.05)$ after Fisher exact test.

\subsection{Small-Scale Gradient Tests}

This experimental setup was performed to demonstrate that lower concentrations $\left(\mathrm{AC}_{20}\right)$ in a contamination gradient do not influence the number of organisms reaching a higher concentration $\left(\mathrm{AC}_{50} / \mathrm{AC}_{80}\right)$. In these experiments, two combinations were used $\left(\mathrm{CT}-\mathrm{AC}_{20}-\mathrm{AC}_{50}\right.$ and $\left.\mathrm{CT}-\mathrm{AC}_{20}-\mathrm{AC} \mathrm{C}_{80}\right)$ which were tested against the respective controls with no intermediate concentration $\left(\mathrm{CT}-\mathrm{CT}-\mathrm{AC} \mathrm{C}_{50}\right.$ and $\left.\mathrm{CT}-\mathrm{CT}-\mathrm{AC} \mathrm{C}_{80}\right)$. The percentage of individuals found in the last section $\left(\mathrm{AC}_{50}\right.$ or $\left.\mathrm{AC}_{80}\right)$ of the three compartment test units, for both the control $\left(\mathrm{CT}-\mathrm{CT}-\mathrm{AC} \mathrm{C}_{\mathrm{x}}\right)$ and test $\left(\mathrm{CT}-\mathrm{AC}_{20}-\mathrm{AC}_{\mathrm{x}}\right)$ combinations is presented in Figure 4.

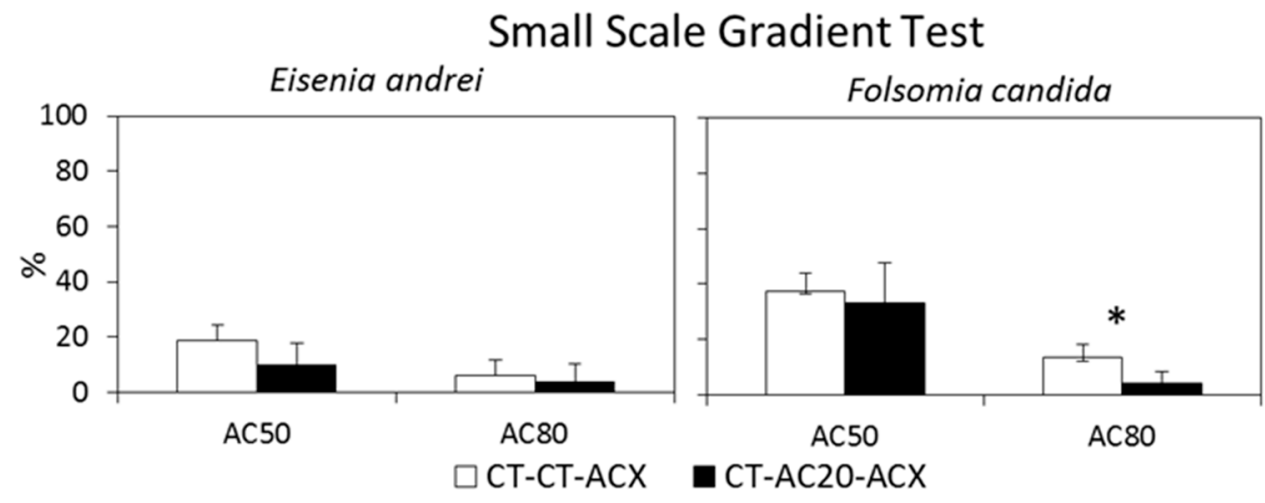

Figure 4. Small-scale gradient tests with Eisenia andrei and Folsomia candida. Percentage of individuals (average \pm standard deviation; $n=5$ ) in the section with the highest copper contaminated soil in three compartment test units combining uncontaminated soil (CT) with copper contaminated soils $\left(\mathrm{AC}_{20}, \mathrm{AC}_{50}\right.$ or $\left.\mathrm{AC}_{80}\right)$ using as intermediate concentrations $\mathrm{CT}$ (white bars) or $\mathrm{AC}_{20}$ (black bars) concentrations. * indicates a significant difference between combinations with and without an $\mathrm{AC}_{20}$ intermediate concentration $(p \leq 0.05)$ after Fisher exact test.

In these experiments, no mortality was observed for E. andrei and the mortality of F. candida was, on average, lower than $5 \%$ in all combinations. No significant differences between the control $\left(\mathrm{CT}-\mathrm{CT}-\mathrm{AC} \mathrm{C}_{\mathrm{x}}\right)$ and test $\left(\mathrm{CT}-\mathrm{AC}_{20}-\mathrm{AC}_{\mathrm{x}}\right)$ distributions in combinations with the same $\mathrm{AC}_{\mathrm{x}}$ were found for $E$. andrei. For F. candida, a significant difference between the control and test distributions was found only for combinations with $\mathrm{AC}_{80}(p=0.02$; Figure 3). 


\section{Discussion}

The avoidance $\mathrm{AC}_{50}$ values obtained for E. andrei (49.5 mg Cu/ $\mathrm{kg} \mathrm{DW}$ ) were lower than the previously reported $\mathrm{AC}_{50}$ values of $181.1 \mathrm{mg} / \mathrm{kg}$ and $94.08 \mathrm{mg} / \mathrm{kg}$, in Lufa 2.2 [34] and OECD artificial soil [35], respectively, but were much higher than the $\mathrm{AC}_{50}$ value of $1.7 \mathrm{mg} / \mathrm{kg}$ reported by Greenslade and Vaughan [36], also in OECD artificial soil. All reported studies followed similar procedures and differences in sensitivity would most likely be due to other factors such as differences in soil properties, the source of copper used for spiking or the test species used.

For soil properties, it is known that properties such as $\mathrm{pH}$, organic carbon content, clay content and cation-exchange capacity influence the toxicity of copper in chronic assays [37], but the extent of their contribution especially for behavioral endpoints is still not fully understood. In fact, while soil properties such as $\mathrm{pH}$ are good predictors of metal solubility, it is still not possible to infer toxicity based on metal solubility [38].

In addition to soil properties, the source of copper used for soil spiking (i.e., copper sulphate, copper nitrate, copper oxide, etc.) could affect the sensitivity of organisms by affecting copper bioavailability in soil [39]. Copper form, could in part explain the large difference in sensitivity observed in both studies using OECD soil $[35,36]$ but unfortunately, one of the studies conducted in OECD soil did not report the source of copper used for spiking [36]. For the remaining studies, one used copper nitrate [35] and both our study and the study with Lufa 2.2 soil [34] used copper sulfate.

Finally, unlike the remaining studies, which were conducted with E. andrei, the study by Xing et al. [35] used the species E. fetida which, despite having comparable sensitivity, could, in conjunction with the other factors, also contribute to some of the differences observed. Further information and examinations would be required to understand these differences in sensitivity especially for both the studies conducted in OECD soil.

Regarding F. candida, the $\mathrm{AC}_{50}$ values obtained $(1007.71 \mathrm{mg} / \mathrm{kg}$ ) were much higher than those reported in the literature $(61.2 \mathrm{mg} / \mathrm{kg}$ [36] and 18 and $17 \mathrm{mg} / \mathrm{kg}$ [40]). This difference could be due to differences in copper form used for spiking (not reported in either studies) and soil properties (for Greenslade and Vaughn [36]) which as explained above, can affect copper toxicity to soil organisms. Additionally, for the study conducted by Boiteau et al. [40], differences could be due to the methodology applied, where unlike the remaining studies conducted in soil, the avoidance $\mathrm{AC}_{50}$ was only determined using a Petri dish method.

In the individual placement tests, it was demonstrated that the position in which earthworms and collembolans are placed in a dual chamber avoidance test does not influence their final distribution. Only in one treatment was there a significant difference observed, for E. andrei when individuals were placed in the test soil at the $\mathrm{AC}_{50}$ level. Thus, overall, the standard procedure used in avoidance tests (placing individuals in the middle line) provides the same response as if a recolonization scenario (placing the individuals in the control soil) or avoidance scenario (placing individuals in contaminated soil) is considered. This empirically demonstrates the avoidance-recolonization hypothesis, i.e., individuals which do no avoid a certain soil are able to colonize it $\left(A C_{x}=R C_{(100-x)}\right)$. Results obtained corroborate those found by Heupel [41] that demonstrated that in dual chamber avoidance tests placing individuals in the control or in a soil spiked with the fungicide Betanal, the same final distribution is observed for several collembolan species (including F. candida).

Regarding the influence of lower concentrations in a contamination gradient, the overall results experimentally demonstrate that intermediate copper concentrations did not influence the dispersal of colonizers to higher copper concentrations in a contamination gradient except for one combination for F. candida (borderline $p$ value of 0.02 ). For F. candida, the influence of an intermediate concentration detected could be due to a factor of time and scaling. Further research exploring larger temporal incubation periods would be interesting to check how time influences the dispersal and avoidance behavior of organisms when exposed to a gradient of contamination. 
Overall, the results obtained support that individuals which are not sensitive enough to avoid a higher concentration of contaminant are also equally insensitive to lower concentrations of contaminants. As such, the expected avoidance response of the test organisms to a certain copper concentration is not affected by its previous exposure to lower concentrations. This is an important demonstration for the avoidance-recolonization hypothesis in that modelling the recovery potential of the most contaminated patches is not dependent on the surrounding patches with lower concentrations. This is particularly important for their application in risk assessment schemes where the full extent of the contamination patchiness is not always known.

In the scientific literature, dispersal and avoidance behavior for metal contaminated gradients, has been previously considered. Bengtsson et al. [42] for instance found that modelled distributions in a gradient of metal contamination, presented the closest fit to observed distributions when individuals were able to detect differences between metal concentrations, as they moved between soils and remained in the less contaminated ones. Additionally, Meli et al. [19], found when modelling the spatial distribution of F. candida in simulated copper contaminated patches, that avoidance behavior acts as a key mechanism allowing for non-contaminated patches to act as population reservoirs and donor areas in heterogeneous contamination scenarios. This originates a decrease in extinction probability of the population when compared to scenarios with a spatially homogeneous contamination, and a more realistic assessment of the risk for the species. The shift in the distribution of organisms due to contamination was also demonstrated in a microcosm experiment with patchily contaminated soil that found that microarthropods avoided the more contaminated soil patches which had lower abundances than clean soil patches [26].

The current study as well as previous research have highlighted the importance and potential of measuring avoidance response when predicting/modelling the recolonization of contaminated habitats and, ultimately, ecological recovery. Specifically, the avoidance-recolonization concept can allow for existing avoidance data to be selected and implemented in modeling approaches.

In fact, the avoidance-recolonization hypothesis demonstrated here for soil with the model species, F. candida and E. andrei (individual placement and small-scale gradient experiments), has also previously been demonstrated in the aquatic compartment using the model species Daphnia magna [28]. In the aquatic avoidance study, placing D. magna in the least contaminated compartment or a uniform distribution along different compartments of a contamination gradient produced a similar distribution and $\mathrm{AC}_{50}$ and $\mathrm{RC}_{50}$ values were not significantly different.

In demonstrating the avoidance-recolonization concept, it inherently demonstrates that the recolonization of a contaminated soil is a density-dependent process modulated by organism dispersal and contaminant concentrations over time. However, further research is still required and must be carefully considered when looking to validate the approach and explore predictions at larger temporal and spatial scales.

From the contaminant perspective, it is important to consider the fate of the contaminant in soil but also its mechanisms of action, which can affect avoidance behavior dynamics and consequently recolonization processes. For instance, dimethoate was found to impair the locomotion of F. candida providing false negative avoidances [43] and etofenprox (under the formulation Trebon 30 EC) was found to promote locomotory hyperactivity followed by very reduced locomotory activity [44].

In addition to contaminant mode of action, the interaction between time, population density and resource availability will play an important role at larger and more realistic scales. Specifically, there could be a cost benefit response to consider where organisms will only look to recolonize surrounding patches if habitat or resource conditions are more favorable. The role of time on avoidance behavior has been previously explored and did not appear to play a significant role, but the timescales considered were up to a maximum of 7 days while for more realistic timescales (i.e., months) these dynamics might change [45]. 
Finally, the ultimate goal for risk assessment of contaminated soils is to understand the role of avoidance behavior on the recovery and recolonization processes for natural communities. In this sense, the current avoidance-recolonization concept provides an important first step and conceptual framework for modelling approaches to understand the role of avoidance behavior in recolonization processes but is limited to the available data for the currently used model species. In order to understand and extrapolate this information for natural communities, will require a good understanding of their ecological traits (i.e., dispersal ability), how species interactions affect avoidance behavior dynamics and that either, currently tested species in avoidance tests are adequately representative of sensitivities in natural communities or a better understanding of their chemical sensitivity.

\section{Conclusions}

Overall, while further research is necessary, this study demonstrated the avoidancerecolonization hypothesis by evidencing that organisms which avoid a soil cannot recolonize that same soil $\left(\mathrm{AC}_{\mathrm{x}}=\mathrm{RC}_{(100-\mathrm{x})}\right)$. As such, standard procedures provide the same response as if a recolonization or an avoidance scenario is considered. Additionally, it was demonstrated that an organism's recolonization of a contaminated soil patch is not affected by lower intermediate patches along a gradient of contamination. As a result, avoidance concentrations could be the tool needed to help understand the recolonization potential of a contaminated soil in spatial modelling approaches. While this concept only implies a paradigm shift (from avoidance to recolonization), its application for modelling tools is extremely valuable. In fact, in spatially based population models if contaminant concentrations, dispersal ability and sensitivity of organisms are well known, it should be possible to predict the necessary "time to recovery" at realistic spatial scales when considering both internal and external recovery processes.

Supplementary Materials: The following supporting information can be downloaded at: https: / / www.mdpi.com/article/10.3390/toxics10030127/s1. The data for metal concentrations and avoidance experiments are provided in the supplementary data (DataRC.xlx).

Author Contributions: Conceptualization, R.R. and J.P.S.; Methodology, M.R., T.N.-d.-L. and J.P.S.; Investigation, M.R.; Formal Analysis, M.R., T.N.-d.-L. and J.P.S.; Writing—Original Draft Preparation, M.R.; Writing-Review and Editing, T.N.-d.-L., R.R. and J.P.S.; Visualization, M.R.; Supervision, J.P.S. All authors have read and agreed to the published version of the manuscript.

Funding: This research was funded by the Portuguese institute, Instituto do Ambiente Tecnologia e Vida (IATV). The work was carried out at the R\&D Unit Center for Functional Ecology-Science for People and the Planet (CFE), with reference UIDB/04004/2020, funded by FCT/MCTES through national funds (PIDDAC).

Institutional Review Board Statement: Not applicable.

Informed Consent Statement: Not applicable.

Data Availability Statement: Data are available as Supplementary Material.

Conflicts of Interest: The authors declare no conflict of interest.

\section{References}

1. Brock, T.; Arts, G.; Matlby, L.; Van den Brink, P. Aquatic risks of pesticides, ecological protection goals, and common aims in European Union legislation. Integr. Environ. Assess. Manag. 2006, 2, 20-46. [CrossRef]

2. Nienstedt, K.M.; Brock, T.C.M.; van Wensem, J.; Montforts, M.; Hart, A.; Aagaard, A.; Alix, A.; Boesten, J.; Bopp, S.K.; Brown, C.; et al. Development of a framework based on an ecosystem services approach for deriving specific protection goals for environmental risk assessment of pesticides. Sci. Total Environ. 2012, 415, 31-38. [CrossRef] [PubMed]

3. Van der Linden, A.M.A.; Boesten, J.J.T.; Brock, T.C.M.; Van Eekelen, G.M.A.; Horst, M.M.S.; Montforts, M.H.M.M.; Pol, J.W. Revised Proposal for the Risk Assessment of Persistence of Plant Protection Products in Soil; RIVM: Bilthoven, The Netherlands, 2008; ISBN 978-90-6960-198-4. 
4. Ockleford, C.; Adriaanse, P.; Berny, P.; Brock, T.; Duquesne, S.; Grilli, S.; Hernandez-Jerez, A.F.; Bennekou, S.H.; Klein, M.; Kuhl, T.; et al. Scientific Opinion addressing the state of the science on risk assessment of plant protection products for in-soil organisms. EFSA J. 2017, 15, e04690. [CrossRef] [PubMed]

5. Lange, H.; Lahr, J.; Pol, V.; Wessels, Y.; Faber, J. Ecological vulnerability in wildlife: An expert judgment and multicriteria analysis tool using ecological traits to assess relative impact of pollutants. Environ. Toxicol. Chem. 2009, 28, 2233-2240. [CrossRef]

6. Alvarez, T.; Frampton, G.; Goulson, D. The role of hedgerows in the recolonisation of arable fields by epigeal Collembola. Pedobiologia 2000, 44, 516-526. [CrossRef]

7. Frampton GGould, P.; Van den Brink, P.; Hendy, E. Type 'A' and 'B' recovery revisited: The role of field-edge habitats for Collembola and macroarthropod community recovery after insecticide treatment. Environ. Pollut. 2006, 145, 874-883. [CrossRef]

8. Marinissen, J.C.Y.; Van den Bosch, F. Colonization of new habitats by earthworms. Oecologia 1992, 91, 371-376. [CrossRef]

9. Ojala, R.; Huhta, V. Dispersal of microarthropods in forest soil. Pedobiologia 2001, 45, 443-450. [CrossRef]

10. Auclerc, A.; Ponge, J.F.; Barot, S.; Dubs, F. Experimental assessment of habitat preference and dispersal ability of soil springtails. Soil Biol. Biochem. 2009, 41, 1596-1604. [CrossRef]

11. Caro, G.; Decaëns, T.; Mathieu, J. The dispersal of the earthworm Aporrectodea giardi responds faster to habitat quality than to cumulative use of habitat in experimental conditions. Appl. Soil Ecol. 2013, 71, 45-47. [CrossRef]

12. Mathieu, J.; Barot, S.; Blouin, M.; Caro, G.; Decaëns, T.; Dubs, F.; Dupont, L.; Jouquet, P.; Nai, P. Habitat quality, conspecific density, and habitat pre-use affect the dispersal behaviour of two earthworm species, Aporrectodea icterica and Dendrobaena veneta, in a mesocosm experiment. Soil Biol. Biochem. 2010, 42, 203-209. [CrossRef]

13. Fenoglio, S.; Cucco, M.; Bo, T.; Gay, P.; Malacarne, G. Colonisation by ground and edaphic invertebrates of soil patches with different pollution levels. Period. Biol. 2007, 109, 37-45.

14. Holmstrup, M.; Hornum, H.D. Earthworm colonisation of abandoned arable soil polluted by copper. Pedobiologia 2012, 55, 63-65. [CrossRef]

15. Forbes, V.E.; Calow, P.; Grimm, V.; Hayashi, T.; Jager, T.; Palmqvist, A.; Pastorok, R.; Salvito, D.; Sibly, R.; Spromberg, J.; et al Integrating population modeling into ecological risk assessment. Integr. Environ. Assess. Manag. 2010, 6, 191-193. [CrossRef] [PubMed]

16. Forbes, V.E.; Calow, P.; Sibly, R.M. The extrapolation problem and how population modeling can help. Environ. Toxicol. Chem. 2008, 27, 1987-1994. [CrossRef]

17. Grimm, V.; Thorbek, P. Population models for ecological risk assessment of chemicals: Short introduction and summary of a special issue. Ecol. Model. 2014, 280, 1-4. [CrossRef]

18. Hamda, N.T.; Forbes, V.E.; Stark, J.D.; Laskowski, R. Stochastic density-dependent matrix model for extrapolating individual-level effects of chemicals to the population: Case study on effects of Cd on Folsomia candida. Ecol. Model. 2014, 280, 53-64. [CrossRef]

19. Meli, M.; Auclerc, A.; Palmqvist, A.; Forbes, V.E.; Grimm, V. Population-level consequences of spatially heterogeneous exposure to heavy metals in soil: An individual-based model of springtails. Ecol. Model. 2013, 250, 338-351. [CrossRef]

20. Meli, M.; Palmqvist, A.; Forbes, V.E.; Groeneveld, J.; Grimm, V. Two pairs of eyes are better than one: Combining individual-based and matrix models for ecological risk assessment of chemicals. Ecol. Model. 2014, 280, 40-52. [CrossRef]

21. ISO 17512-1; Soil Quality-Avoidance Test for Testing the Quality of Soils and Effects of Chemicals on Behaviour-Test with Earthworms (Eisenia fetida and Eisenia andrei). International Organization for Standardization: Paris, France, 2007.

22. ISO 17512-2; Soil quality_Avoidance Test for Determining the Quality of Soils and Effects of Chemicals on Behaviour-Part 2: Test with Collembolans (Folsomia candida). International Organization for Standardization: Geneva, Switzerland, 2008.

23. Natal-da-Luz, T.; Ribeiro, R.; Sousa, J.P. Avoidance tests with Collembola and earthworms as early screening tools for site-specific assessment of polluted soils. Environ. Toxicol. Chem. 2004, 23, 2188-2193. [CrossRef]

24. Natal-da-Luz, T.; Römbke, J.; Paulo Sousa, J. Avoidance tests in site-specific risk assessment-Influence of soil propertires on the avoidance response of collembola and earthworms. Environ. Toxicol. Chem. 2008, 27, 1112-1117. [CrossRef] [PubMed]

25. Niemeyer, J.C.; Moreira-Santos, M.; Nogueira, M.A.; Carvalho, G.M.; Ribeiro, R.; Silva, E.M.; Sousa, J.P. Environmental risk assessment of a metal-contaminated area in the Tropics. Tier I: Screening phase. J. Soils Sediments 2010, 10, 1557-1571. [CrossRef]

26. Salminen, J.; Sulkava, P. Distribution of soil animals in patchily contaminated soil. Soil Biol. Biochem. 1996, $28,1349-1355$. [CrossRef]

27. Haimi, J.; Paavola, S. Responses of two earthworm populations with different exposure histories to chlorophenol contamination Environ. Toxicol. Chem. 1998, 17, 1114-1117. [CrossRef]

28. Araújo, C.V.M.; Moreira-Santos, M.; Ribeiro, R. Stressor-driven emigration and recolonisation patterns in disturbed habitats. Sci. Total Environ. 2018, 643, 884-889. [CrossRef]

29. LNEC-E 239; Solos-Análise Granulométrica por Peneiração Húmida. Laboratório Nacional de Engenharia Civil (LNEC): Lisboa, Portugal, 1970.

30. ISO 11274; Soil Quality—Determination of Water-Retention Characteristic-Laboratory Methods. International Organization for Standardization: Paris, France, 2007.

31. Kjeldahl, J. Neue Methode zul Bestimmung des Stickstoffs in organischen Körpern. Z. Anal. Chem. 1883, 22, 366-382. [CrossRef]

32. ISO 11260; Soil Quality-Determination of Effective Cation Exchange Capacity and Base Saturation Level Using Barium Chloride Solution. International Organization for Standardization: Geneva, Switzerland, 2007.

33. Sakuma, M. Probit analysis of preference data. Appl. Entomol. Zool. 1998, 33, 339-347. [CrossRef] 
34. Loureiro, S.; Soares, A.M.V.M.; Nogueira, A.J.A. Terrestrial avoidance behaviour tests as screening tool to assess soil contamination. Environ. Pollut. 2005, 138, 121-131. [CrossRef]

35. Xing, Y.; Luo, J.; Zhang, J.; Li, B.; Gong, X.; Liu, Z.; Liu, C. Effects of single and combined exposures to copper and benzotriazole on Eisenia fetida. Chemosphere 2017, 186, 108-115. [CrossRef]

36. Greenslade, P.; Vaughan, G.T. A comparison of Collembola species for toxicity testing of Australian soils. Pedobiologia 2003, 47, 171-179. [CrossRef]

37. Criel, P.; Lock, K.; Van Eeckhout, H.; Oorts, K.; Smolders, E.; Janssen, C.R. Influence of soil properties on copper toxicity for two soil invertebrates. Environ. Toxicol. Chem. 2008, 27, 1748-1755. [CrossRef] [PubMed]

38. Smolders, E.; Oorts, K.; Sprang, P.V.; Schoeters, I.; Janssen, C.R.; McGrath, S.P. Toxicity of trace metals in soi as affected by soil type and aging after contamination: Using calibrated bioavailability models to set ecological soil standards. Environ. Toxicol. Chem. 2009, 28, 1633-1641. [CrossRef] [PubMed]

39. Arnold, R.E.; Hodson, M.E.; Black, S.; Davies, N.A. The influence of mineral solubility and soil solution concentration on the toxicity of copper to Eisenia fetida Savigny. Pedobiologia 2003, 2, 622-632. [CrossRef]

40. Boiteau, G.; Lynch, D.H.; Mackinley, P. Avoidance tests with Folsomia candida for the assessment of copper contamination in agricultural soils. Environ. Pollut. 2011, 159, 903-906. [CrossRef] [PubMed]

41. Heupel, K. Avoidance response of different collembolan species to Betanal. Eur. J. Soil Biol. 2002, 38, 273-276. [CrossRef]

42. Bengtsson, G.; Rundgren, S.; Sjögren, M. Modelling dispersal distances in a soil gradient: The influence of metal resistance, competition, and experience. Oikos 1994, 71, 13-23. [CrossRef]

43. Pereira, C.M.S.; Novais, S.C.; Soares, A.M.V.M.; Amorim, M.J.B. Dimethoate Affects Cholinesterases in Folsomia candida and Their Locomotion-False Negative Results of an Avoidance Behaviour Test. Sci. Total Environ. 2013, 443, 821-827. [CrossRef]

44. Szabó, B.; Seres, A.; Bakonyi, G. Folsomia candida (collembola) locomotor activity pattern is changed by a neurotoxicant pesticide. Acta Zool. Acad. Sci. Hung. 2018, 64, 355-368. [CrossRef]

45. Natal-da-Luz, T.; Amorim, M.J.B.; Römbke, J.; Sousa, J.P. Avoidance tests with earthworms and springtails: Defining the minimum exposure time to observe a significant response. Ecotoxicol. Environ. Saf. 2008, 71, 545-551. [CrossRef] 